\title{
Apgar Score Decreased or Low
}

National Cancer Institute

\section{Source}

National Cancer Institute. Apgar Score Decreased or Low. NCI Thesaurus. Code C50416.

An Apgar score less than seven. 